\title{
PROVA E VERDADE NO PROCESSO CIVIL - CONTRIBUTO PARA O ESCLARECIMENTO DA BASE IDEOLÓGICA DE CERTAS POSIÇÕES PRETENSAMENTE TÉCNICAS*
}

JUAN MONTERO AROCA*

\section{O questionamento da verdade como função da prova}

Quando se fala em prova no processo jurisdicional - seja no civil, seja no penal -, uma das primeiras perguntas que se deve fazer é no sentido de qual é a sua função ou, perguntado de outra forma, qual o papel que a prova cumpre no processo. Normalmente a resposta é dada relacionando-se prova com verdade, mas essa relação não é unívoca.

\subsection{A verdade no processo, não em abstrato}

Tradicionalmente a função da prova vem sendo referida como a busca e o descobrimento da verdade, como já apontamos, e neste sentido se pronunciou toda a doutrina do século XIX para a qual "as provas são os diversos meios pelos quais a inteligência chega ao descobrimento da verdade" ${ }^{4}$. Neste contexto, não se estava dando uma resposta política, senão simplesmente dizendo, em palavras francas, sem complicações ideológicas ou técnicas, o que parecia mais adequado ao processo, a qualquer processo.

Sem pretender propor aqui e agora questões metafísicas (=verdade a que se chega pela inteligência) ou históricas (=verdade que nos narram outras pessoas), pode-se afirmar que hoje se reconhece comumente que essa aspiração - nada menos que “a verdade”, aquela a que Pôncio Pilatos não esperou para

\footnotetext{
${ }^{*}$ Catedrático de Direito Processual na Universidad de Valencia. Ex-magistrado do Tribunal Superior de Justiça da Comunidade Valenciana. Advogado na Espanha.

*Tradução de Glauco Gumerato Ramos.

${ }^{4}$ BONNIER, E. Tratado teórico y práctico de las pruebas en derecho civil y en derecho penal, I, 5. ${ }^{a}$ edición, Madrid, 1928 (tradução de De Vicente y Caravanrtes, cuja $1^{a}$ edição é de 1869, e notas de Rives Martí), p. 9; mas se pode recordar de vários outros autores, entre os quais destacamos RICCI, F., Tratado de las pruebas, tradução de Buylla y Posada, Madrid, s/d, tomo I, p. 22: "La prueba, en efecto, no es um fin por si mismo, sino un medio dirigido a la consecusión de un fin, que consiste en el descubrimiento de la verdad". En España VICENTE Y CARAVANTES, José de. Tratado histórico crítico filosófico de los procedimientos judiciales en materia civil, según la nueva Ley de Enjuiciamiento, II, Madrid, 1865, p. 124.
} 
ouvir - era demais ambiciosa ${ }^{5}$ e, sobretudo, nem sempre compatível com os princípios e regras conformadoras do processo civil.

Não se trata apenas de algo tão elementar como é o reconhecimento das limitações em que se encontra o homem na hora de alcançar verdades que se podem qualificar de absolutas. Trata-se, mas singelamente, de assumir que o processo se configura conforme uma série de princípios que são tão importantes quanto a busca da verdade na hora de se demonstrar os fatos que serão tomados em consideração na sentença, como, por exemplo, os são os princípios: da condição de "terceiro" do juiz, do contraditório, da ampla defesa, da igualdade das partes.

Dito isso, imediatamente deve-se afirmar - para evitar equívocos - que no processo e na prova necessariamente deve existir a intenção de se verificar, da maneira mais próxima possível da realidade, as afirmações fáticas feitas pelas partes, uma vez que a constatação dos limites impostos ao homem, bem como os princípios processuais que se lhe aplicam, simplesmente não pode levar a que se renuncie que a sentença se baseie num repertório de fatos provados que corresponda o mais adequadamente possível àquilo que realmente aconteceu.

Portanto, a função da prova e o papel que ela representa no processo não pode existir no vazio das coisas abstratas. Ao contrário, seu regramento deve estar devidamente organizado nos ordenamentos jurídicos concretos e isso supõe sua adequação aos princípios e regras que orientam o processo e, mais do que isso, a função jurisdicional.

\subsection{A função da jurisdição}

Sobre a função da jurisdição, parece claro que hoje se mantêm substancialmente dois posicionamentos:

\footnotetext{
${ }^{5}$ Em geral se pode ver em GIULIANI, A., Il concetto di prova (contributo alla logica giuridica), Milano, 1961, y Prova in generale, a) filosofia del diritto, en Enciclopedia del Diritto, XXXVII, Milano, 1988, pp. 519-579; WRÓBLEWSKY, J., Sentido y hecho en el derecho y especialmente El problema de la asi llamada verdad judicial, San Sebastián, 1975; CHIARLONI, S., Processo civile e verità, en Questione giustizia, 1987, núm. 3; TARUFFO, M., La prova dei fatti giuridici, Milano, 1992, existe tradução espanhola de Ferrer Beltrán, La prueba de los hechos, Madrid, 2002; também dele mesmo Funzione della prova: la funzione dimostrativa, en Rivista Trimestrale di Diritto e Procedura Civile, 1997, núm. 3, e agora em "Sui confini. Scritti sulla giustizia civile”, Bologna, 2002, pp. 305-328; GASCÓN ABELLÁN, M., Los hechos en el derecho. Bases argumentales de la prueba, Madrid, 1999; FERRER BELTRÁN, J., Prueba y verdad en el Derecho, Madrid, 2002.
} 
$1^{\circ}$ ) Há aqueles que sustentam que a jurisdição é voltada para a atuação do Direito objetivo através da aplicação da norma ao caso concreto, de modo que ao Estado corresponderia assegurar a respectiva atuação toda vez que os respectivos comandos não tenham sido voluntariamente observados pelo seu destinatário ${ }^{6}$. Nesse contexto, a norma que deve ser aplicada pela Administração Pública para ser atingida uma certa finalidade é a mesma norma a ser aplicada pelo órgão jurisdicional como objeto de sua atividade institucional, no sentido de que a respectiva atividade se exercita com a finalidade ou - pelo menos com o fim principal de assegurar o respeito ao Direito objetivo. Nessa perspectiva, que para alguns é simplesmente publicista, não obstante a qualifiquemos como autoritária, a categoria "verdade", ainda que se admita ser ela relativa, converte-se em parte essencial da função do juiz no processo, o qual em boa medida deixa de ser um terceiro entre as partes, além de pôr em risco sua imparcialidade. ${ }^{7}$

$2^{\circ}$ ) Outros, como nós, sustentam que a função da jurisdição deve orientarse no fato de que o juiz, sendo terceiro e imparcial, é o último garante dos direitos que a ordem jurídica reconhece ao indivíduo, seja qual for o ramo do Direito que se tenha em conta. Naturalmente os direitos que mais importam são

\footnotetext{
${ }^{6}$ Politicamente esta concepção respondeu claramente a uma ideia autoritária do Direito, que via nele a vontade do Estado e em sua observância o respeito à autoridade deste Estado; nela fica na sombra o interesse individual e a defesa do direito subjetivo, e surge em primeiro plano o interesse público na observância do direito objetivo. O importante não é o interesse dos particulares; o importante é que se cumpra a previsão geral da lei enquanto nela se tem o interesse público. Por isso todas as manifestações destas concepções, em menor ou maior medida, têm um substrato autoritário que não se pode esconder sob referências ao "social". Neste sentido, se pode ver em CALAMANDREI, Istituzioni di Diritto processuale civile secondo il nuovo codice, Parte Prima, Padova, 1941, p. 65.

Ao contrário do que pode parecer, estas concepções não nascem no processo penal, no qual se podia supor já que, em princípio, trata-se de aplicação de um ramo do direito público, como é o penal, que poderia prevalecer o interesse geral, senão que sua origem se encontra na concepção autoritária do processo civil a que respondem o socialismo (os códigos da antiga União Soviética) e o fascimo (o Código italiano de 1940), ainda que acabe sendo aplicado ao processo penal e neste se trata de fazer prevalecer a segurança da sociedade frente à liberdade do indivíduo.

${ }^{7}$ Exemplo muito claro dessa concepção pode-se constatar em escrito do juiz federal brasileiro CABRAL, Antonio do Passo, Il principio del contraddittorio como diritto d'influenza e dovere di dibattito, na Rivista di Diritto Processuale, 2005, 2, p. 453. Segundo o Autor, o direito processual (em geral) abandonou há muito tempo as algemas do individualismo, consolidando a concepção publicista do processo; sendo direito público, deve se identificar no exercício da atividade jurisdicional o esforço do Estado para realizar, por meio da jurisdição, alguns fins que lhe são próprios e que precedem aos interesses das partes: objetivos sociais e políticos entre os quais deve ser sublinhado o de assegurar a participação popular no processo; isto é, o processo é um meio a servi-lo de determinados fins estatais e a função jurisidicional é o caminho para alcançar os fins políticos do Estado democrático. Claro que não se disse quais são esses fins, ainda que pareça que permite distinguir entre um Estado que serve as pessoas e um Estado que se serve das pessoas...
} 
os fundamentais, eis que os de maior transcendência, mas o certo é que a garantia se refere a todos os Direitos. Na aplicação do direito privado deve-se, por meio do processo, fazer com que o particular veja que seus direitos subjetivos - de caráter econômico, ou não -, tal como afirmados, foram examinados e decididos conforme as garantias próprias do processo.

Dessa maneira resulta que a tutela dos direitos dos particulares por meio da atuação jurisdicional tem que se basear no império da Lei, por um lado - esta tomada em sua acepção de representar o Direito - e, por outro, conforme as regras que determinam o funcionamento do instrumento que é o processo. A partir desta posição, que é privatista e liberal, a "verdade" - sempre relativa se converte em meio para cumprir com a função de garantia.

\subsection{As pretendidas funções do processo}

Ultimamente tem-se pretendido distinguir - grosso modo - entre duas posições doutrinárias acerca da função do processo ${ }^{8}$ :

$1^{\circ}$ ) A primeira delas consiste, apenas, em resolver as controvérsias, pondo fim aos conflitos entre particulares, aqui entendido que as consequências desta pretendida posição estão radicadas, dentre outros motivos, no fato de que não importa o conteúdo da sentença, é dizer, a qualidade da decisão não se toma em conta, pois se trata apenas de como se chega à decisão - por meio de um processo justo -, pouco importando o conteúdo desta. Neste contexto se diz que, para essa postura dogmática, não interessa a verdade e que, por isso mesmo, tão pouco se admitem os poderes probatórios do juiz.

$2^{\circ}$ ) Contrariamente a esta posição, apresenta-se a concepção para a qual o que mais importa é a qualidade da decisão judicial, decisão que se deve basear numa aplicação correta e racionalmente justificada do Direito, e por isso mesmo se deve alcançar a verdade dos fatos, a serviço da qual devem estar os poderes instrutórios do juiz.

A contraposição entre essas duas posturas dogmáticas é uma clara manipulação maniqueísta, uma vez que não existe ninguém que chegue a

\footnotetext{
${ }^{8}$ Constata-se o ponto, por exemplo, em TARUFFO, M., Poteri probatori delle parti e del guidice in Europa, na Revista Trimestrale di Diritto e Procedeura Civile, 2006, n. 2, pp. 468 e ss.
} 
sustentar tão descaradamente que o conteúdo da sentença seja, política e juridicamente, indiferente. O verdadeiro debate tem sido centrado, e assim se deve seguir fazendo, em determinar qual é a melhor maneira de regular o processo para que, de um lado, as partes possam alcançar a tutela efetiva de seus direitos e que, por outro, possa o juiz cumprir com sua função de garante último desses direitos, sendo que nesse debate nada têm a ver as posições ideológicas que, de modo absurdo, descreve Taruffo.

Além do mais, Taruffo se permite fazer afirmações - aliás, carentes de demonstração - radicalmente contrárias aos sistemas jurídicos ocidentais. Por exemplo, afirma literalmente que: “É notório e está historicamente confirmado que o modo menos eficiente para descobrir a verdade dos fatos no processo é o de confiar-se exclusivamente na iniciativa probatória das partes". Se esta contundente afirmação fosse precisa, seria óbvio que todos os ordenamentos jurídicos do mundo ocidental deveriam ser radicalmente reformados, especialmente os relativos ao processo penal, pois aí deveriam ser atribuídos completos poderes probatórios - ainda que não exclusivos - aos jurados quando o caso - e ao juiz que o preside. Ao invés disso, o sistema ocidental de justiça se baseou em algo elementar: “As partes são os melhores juízes de sua própria defesa". 9

O fato é que não se pode esquecer algo elementar quando se pretende compreender a doutrina processual - isto é, sua base teórica-, que é exatamente a experiência decorrente da atividade prática daqueles que manejam o processo e que, por isso mesmo, aprendem tanto com a primeira (=doutrina) quanto com a segunda (=prática). Por conta disso é que não se pode admitir a afirmação do mesmo Taruffo quando diz que "em todos os processos existe ao menos uma parte - aquela que sabe que está agindo iniquamente - que não tem interesse algum em que se descubra a verdade". Quando se sustenta esta afirmação, se está desconsiderando a realidade mesma da vida judicial, na qual as partes - as duas partes! - normalmente chegam ao processo - e aqui deixemos de lado os casos patológicos - convencidas de que têm razão em sua causa, ainda que seja em parte. Só quem não tem experiência na realidade processual cotidiana, quem

${ }^{9}$ CHIOVENDA, G., Principios de derecho procesal civil, II, Madrid, 1925, tradução de Casáis y Santaló, p. 183. 
não tenha trabalhado profissionalmente em juízo durante a vida, é que pode fazer uma afirmação dessa natureza, no sentido de que sempre estará sem razão uma das partes. ${ }^{10}$

Somente na perspectiva de uma concepção política autoritária sobre a função jurisdicional, e de seu instrumento que é o processo, é que se pode chegar a sustentar que o papel do advogado é algo "diferente" se comparado com a defesa que deve exercer em relação aos interesses de seu cliente, e que por isso não poderia utilizar todos os meios disponíveis que o ordenamento jurídico-processual põe a sua disposição para o exercício técnico da ampla defesa $^{11}$. O absurdo, baseado numa determinada e evidente concepção ideológica, chega ao extremo de pretender que o advogado deva atuar contrariamente aos interesses de seu cliente e a favor do cumprimento do Direito objetivo, ou seja, se lhe impõe ser imparcial. E, em contrapartida, que o juiz abdique de sua neutralidade/imparcialidade para sempre estar ao lado de uma pretensa "verdade".

E assim se chega ao absurdo de certas construções que propõem um mundo ao contrário do que ele é: advogado imparcial (veracidade, lealdade, boa-fé, colaboração com o juiz) e juiz parcial (perda da neutralidade/imparcialidade a serviço da verdade material).

\subsection{Os princípios do processo}

\footnotetext{
${ }^{10}$ A afirmação que faz TARUFFO pode ser conferida em Poteri probatori delle parti..., p. 477.

${ }^{11}$ Por certo que nesta mesma página indicada na nota de rodapé anterior se descobre o fundo ideológico de TARUFFO quando segue afirmando, e como se isso fosse reprovável: "os defensores não são cientistas que perseguem a busca imparcial e desinteressada da verdade, senão o fazem com o interesse de ressaltar a versão dos fatos que mais convém ao seu cliente, e isso, inclusive, independente da verdade". A surpresa que essa afirmação causa ao leitor é grande, pois os advogados, desde que a profissão existe, têm como função exatamente defender os interesses de seus clientes e para isso devem ressaltar a versão dos fatos que melhor sustenta a respectiva pretensão. O processo civil da nossa civilização se baseou precisamente no fato de que o advogado é alguém parcial, com a função clara de sustentar em juízo as pretensões - de ataque ou defesa - de seus clientes. No processo, imparcial mesmo somente é o juiz, ou será que Taruffo pretende que os advogados também sejam imparciais?

A posturas como essa, só mesmo faltaria acrescentar que as partes e seus defensores têm o dever de atuar conforme os princípios de boa-fé e veracidade, e que o juiz é o "amigo" e colaborador das partes na busca da justiça para - em definitivo - convencermo-nos da concepção totalitária que está na base de afirmações como as aqui apontadas e feitas por Taruffo. Sobre o tema, cf. MOTERO AROCA, J., "Ideología y proceso civil. Su reflejo en la 'buena fe procesal'”, na obra coletiva Ideología y proceso civil, Valencia, 2a ed., 2011.
} 
Os princípios e regras que orientam o processo se consideram elementos que têm que determinar a possibilidade de se alcançar - em maior ou menor grau - a verdade. Por conta disso, é evidente que:

$\left.1^{\circ}\right)$ Um processo regido pelos princípios da oportunidade, dispositivo e da iniciativa da parte em matéria probatória [=aportación], ou seja, um processo regido pelo velho brocardo ne procedat judex ex officio e judex judicare debet secundum allegata et probata partibus, supõe necessariamente que os fatos que importam ao processo são os que foram afirmados pelas partes - e por ninguém mais! -, bem como que a prova deverá ter por objeto somente os fatos controvertidos através de uma atividade verificadora, e não por uma atividade de investigação ${ }^{12}$, já que os meios de prova a serem produzidos são aqueles que foram propostos pelas partes conforme o princípio da legalidade, sendo que na verificação por parte do juiz não vale tudo, pois não se pode sacrificar direitos que se consideram superiores à própria verdade. Não pode servir como base da sentença um fato verificado de modo a que se tenha vulnerado um direito fundamental, como por exemplo, uma prova obtida por meio ilícito. ${ }^{13}$

Além disso, um processo orientado por princípios como o do contraditório e da igualdade das partes, e que é regulado de modo a conferir certas regras voltadas à segurança dessas próprias partes - como a preclusão, por exemplo , não pode negar um e/ou outro a serviço de uma pretendida verdade que estaria por cima das próprias garantias oferecidas pelo processo.

\footnotetext{
${ }^{12}$ Em sentido estrito, a investigação supõe a busca ou descobrimento de alguns fatos desconhecidos e, evidentemente, este não é um pressuposto do processo civil. Nele, as partes têm a faculdade exclusiva de realizar as afirmações de fatos e o julgador se limita a verificar a exatidão dessas afirmações apenas no caso de terem sido negadas ou contraditadas.

${ }^{13}$ Naturalmente que o que dissemos acima não guarda nenhuma relação com doutrinas que distinguem classes de verdade com base em classes de processos. Passou-se a sustentar que se no processo penal a função da prova devia seguir sendo a busca da verdade, que se qualificou de material, no proceso civil bastava uma verdade que se chamou de formal. Se o julgador estava juridicamente limitado na busca dos fatos, o resultado da atividade probatória admitiu que não podia ser a "verdade verdadeira", senão simplesmente uma verdade jurídica, baseada não nas leis da lógica, mas sim fundada em leis jurídicas.

A distinção anterior é absurda, mas foi sustentada pela doutrina (especialmente a alemã, o que pode se cf. em FURNO, C., Teoría de la prueba legal, Madrid, 1954, traduc. de González Collado, p. 22, nota 24) durante décadas e, sobretudo, permitiu aos processualistas penais diferenciar a prova penal da prova civil. O mito da verdade formal foi destruído por Carnelutti simplesmente evidenciando que a verdade não pode ser mais que uma, de modo que, ou a verdade formal coincide com a verdade material, e não é mais que a verdade, ou discrepa dela e por isso não é senão uma não-verdade. Cf. CARNELUTTI, La prueba civil, 1. a edição 1915, e 2. ${ }^{a}$ edicão 1947, com um interessante apêndice de Giacomo P. Augenti; citamos agora por La prueba civil (tradução de Alcalá-Zamora direto da edição italiana de 1947), 2. ${ }^{a}$ edição, Buenos Aires, 2000, p. 21, que recorda que a expressão verdade formal se deve a Möser.
} 
Não se trata apenas do fato de a prova se referir às afirmações fáticas feitas pelas partes, senão também de que o processo está sujeito a certas regras e princípios de tanta importância como, ao menos em tese, possa ser o fato de que o elemento determinante da justiça contida na sentença tenha partido de um conhecimento real dos fatos. No processo, eis que uma série de atos sujeitos a certos princípios, não se pode desconhecer, por exemplo, que as alegações fáticas das partes têm um momento previamente determinado para serem feitas, de modo que, precluída essa oportunidade, não haverá mais espaço para afirmações de outros fatos, bem como não se poderá propor meios de prova fora de determinados momentos processuais. Dessa forma, não se pode ver a preclusão como um obstáculo ao "descobrimento" da verdade, mas sim como um elemento viabilizador de princípios básicos, como o são o contraditório ou a igualdade das partes, e estes princípios são tão irrenunciáveis como a própria base fática sobre a qual se deverá decidir o processo.

Tudo isso indica, sem mais, que a busca da verdade não pode ser a função última da prova civil, entre outros motivos porque o que realmente se persegue através da jurisdição não é meramente declarar de modo absoluto a verdade dos fatos. A jurisdição persegue a tutela dos direitos das partes, direitos esses decorrentes das respectivas afirmações fáticas. Mais ainda, a função da jurisdição através do processo não consiste em declarar certos e determinados fatos, mas sim tutelar direitos subjetivos, e isso se deve fazer conforme a regulamentação principiológico-legal do processo, cuja essência é a própria tutela desses direitos.

$\left.2^{\circ}\right)$ Um modo inquisitivo de aplicar o Direito, vale dizer, determinado pelos princípios da necessidade, da oficialidade e da iniciativa judicial em matéria de prova [=aportación judicial], terá uma situação onde os fatos possam ser trazidos pelo juiz ao processo como reflexo da própria investigação. Cabe dizer que um sistema dessa natureza está, possivelmente, a serviço da verdade, muito embora esta afirmação é tão discutível como a de que o Tribunal da Inquisição foi o mais adequado para atingir a verdade. O que é certo é que este processo já não é mais um ambiente de garantia da tutela dos direitos subjetivos das pessoas, mas sim um meio de assegurar a realização do Direito objetivo.

A rigor, esse "processo" inquisitivo se explica em razão de, através dele, buscar-se um fim político - por exemplo, a construção do socialismo -, sendo 
isso o que mais importa e não os direitos das partes, a não ser como complemento desse fim político. Naturalmente, nessa maneira de se aplicar o Direito objetivo não importam os princípios nem as regras determinantes à dinâmica do processo, sem dizer que garantias fundamentais, como por exemplo a condição de terceiro imparcial que o juiz deve ostentar, acabam sendo postas de lado por carecerem de real sentido, uma vez que prevalece o "político" sobre o "jurídico".

O resultado da contraposição desses sistemas - acusatório e inquisitivo viabilizou que fossem apresentados como opções técnicas ${ }^{14}$, mas isso evidentemente se trata de clara opção política, como veremos a seguir. Contudo, o que importa agora é destacar que a verificação dos fatos é um elemento transcendental no processo, já que só a partir dessa verificação é que se pode tutelar os direitos subjetivos das pessoas. E isso não de qualquer maneira, senão com os condicionamentos que são próprios da jurisdição e do processo, e daí à noção de certeza. ${ }^{15}$

\section{Funções complementares da prova}

Relativizada a busca da verdade, doutrina que considera que o processo é garantia da tutela dos direitos das partes - e não a doutrina autoritária - dividese em correntes não muito bem perfiladas, muito embora as diferenças entre uma e outra sejam de matiz. Assim, é possível distinguir ${ }^{16}$ entre:

\subsection{Fixar fatos}

\footnotetext{
${ }^{14}$ Neste sentido cf. COMOGLIO, Le prove civili, 2. ${ }^{a}$ edição, Torino, 2004, pp. 17 e ss. Em sentido contrário cf. MONTELEONE, G., Manuale di Diritto processuale civile, I, 4. a edição, Padova, 2007, pp. 267-272, para quem a inquisição judicial, sem dar garantia alguma de resultados mais rápidos e melhores, é a expressão de um poder público autoritário, em detrimento das partes.

${ }^{15}$ Ao que acabamos de dizer devem ser acrescentados outros elementos que orientam a maneira de regular o processo. Se nessa regulação se impõem às partes e a seus Advogados os deveres de dizer a verdade e de colaborar com o juiz na busca da verdade, e além disso dota-se o juiz de poderes de coerção, é obvio que se está disposto pelo legislador meios que favoreçam a verdade, mas também o que isso se faz à custa das garantias processuais das partes no processo; cf. MONTERO, J., Ideología y proceso civil. Su reflejo en la "buena fe procesal”, no já citado volume coletivo Ideología y proceso civil, com a bibliografía sobre a boa-fé. ${ }^{16}$ Esta distinção efetuada já em MONTERO, J., La prueba en el proceso civil, 1. a edição, Madrid, 1996, pp. 27-29, e reiterada em edições e em obras posteriores (até 2012, na $7^{\text {a }}$ edição), é tratada criticamente por FERRER BELTRÁN, Prueba y verdad en el Derecho, cit., p. 73-77.
} 
Uma coisa é a fixação dos fatos controvertidos ou a ordenação do uso de determinados procedimentos que servem para estabelecer os fatos conforme o que está disposto na Lei. A Lei regula uma série de mecanismos que o julgador tem que utilizar como sistemas únicos para chegar à fixação dos fatos e essa fixação é a função das normas do direito probatório. Trata-se aqui de que, naturalmente, importa o resultado que se alcance com o processo - o conteúdo da sentença -, mas também a forma como a este resultado se chegou; e se importante é o primeiro, não menos o será o segundo. Em outras palavras poderse-ia dizer que ofim - ou o conteúdo da sentença - não justifica os meios - ou, como a ela se chegou.

Não se está fazendo referência exclusiva entre essas regras e as regras legais de valoração da prova, nem às que determinam quando um fato é controvertido. Inclusive, a prova dos fatos controvertidos, quando se trata da livre valoração, deve-se realizar conforme o sistema legal que lhe é próprio e neste sistema o fator determinante não é o descobrimento da verdade, uma vez que o que importa é deixar formalmente estabelecidos os fatos relevantes que constarão na sentença.

Essas regras são o resultado da intenção de se atingir segurança na determinação dos fatos (utilizando as experiências acumuladas para evitar erros) e fazê-1o com economia de esforços (evitando a realização de atos supérfluos $)^{17}$. Naturalmente, nada impede que com os meios jurídicos de fixação dos fatos se chegue realmente a se descobrir a verdade, o que de outra parte deve ser o normal ${ }^{18}$. Nesta concepção de atividade probatória, a fixação dos fatos controvertidos deve estar de acordo com as regras jurídicas que lhe são próprias.

Os sistemas de fixação dos fatos não podem ser qualificados de formalistas, a não ser que se queira distinguir entre a forma, como garantia, e o formalismo como degeneração da forma, até o extremo de se converter em obstáculo à garantia. ${ }^{19}$

\footnotetext{
${ }^{17}$ Outra vez CARNELUTTI, La prueba civil, cit., p. 19.

18 DÖHRING, E., La investigación del estado de los hechos en el proceso. La prueba. Su práctica y apreciación, Buenos Aires, 1972 (traducão de Banzhaf), p. 6.

${ }^{19}$ Já dizia MONTESQUIEU, L'esprit des lois, VI, 2, y XXIX, 1, que a forma é o preço da segurança, e depois CHIOVENDA, G., Las formas en la defensa judicial del derecho, em "Ensayos de Derecho Procesal Civil", II, Buenos Aires, 1949 (tradução de Santiago Sentís Melendo), p. 123 e ss.
} 


\subsection{Convencer o juiz}

Outra coisa, bem distinta, é a convicção psicológica do julgador no sentido de que a prova é o conjunto de operações através do qual se busca obter o convencimento do juiz a respeito de determinados dados processuais. Relativizada a pretensão de se obter a verdade - é dizer: a realidade objetiva dos fatos -, surge então a função de se alcançar outra realidade - ainda que subjetiva - que é a convicção do juiz. Neste sentido é que dizia Chiovenda que a função de provar se resolve em "criar o convencimento do juiz sobre a existência ou a não existência de fatos relevantes ao processo" ${ }^{20}$.

É natural que esta concepção se veja obrigada a negar ou a tirar valor de elementos que são impostos pela Lei. Dada a existência em todos os ordenamentos jurídicos processuais de meio de prova com valor legal (documentos públicos e às vezes privados, por exemplo), afirmar que a função da prova é gerar a convicção do juiz supõe desconhecer essas regras legais, e por isso se diz que elas são "um resíduo histórico de velhas concepções em estado de contínua superação" 21 .

Por outra parte a convicção acaba por se referir à probabilidade. A certeza se produz quando a inteligência manifesta a realidade de uma afirmação, mas a clareza absoluta só se pode produzir no campo da física ou da matemática, não no do processo, onde só cabe uma certeza moral que se resolve na convicção enquanto medida psicológica da certeza. ${ }^{22}$

\footnotetext{
${ }^{20}$ CHIOVENDA, G., Principios de derecho procesal civil, II, cit., p. 281. No mesmo sentido MANDRIOLI, C., Diritto processuale civile, II, 15. ${ }^{a}$ edição, Torino, 2003, p. 170, se bem que deixa claro que esta definição se mantém porque é a que se presta a críticas menores a partir do lado da relatividade da verdade atingível no processo. Por isso, partindo dessa relatividade, alude à função demonstrativa da prova contra a função persuasiva, o que se põe em relação com a motivação das decisões judiciais.

${ }^{21}$ GUASP, J., La prueba en el proceso civil español: principios fundamentales, primeiro em Publicaciones de la Universidad de Oviedo, Oviedo, 1945 e agora em Estudios Jurídicos, Madrid, 1996, pág. 393. Para ele “o fenômeno da prova taxada é um monstro jurídico que deve ser estudado não na fisiologia mas sim na teratologia do direito", na pág. 428. Em Derecho procesal civil, I, 3. ${ }^{\mathrm{a}}$ edição, 2. ${ }^{\mathrm{a}}$ reimpressão, Madrid, 1977, p. 321, que é sua última obra geral, define a prova como "o ato ou série de atos processuais pelos quais se trata de convencer o Juiz da existência ou inexistência dos dados lógicos que hão de se ter em conta no julgamento". Deve-se ter em conta que só se pode entender Guasp se se adverte que antes tinha escrito um livro contra o direito de disposição das partes sobre o material fático do processo, intitulado Juez y hechos en el proceso civil (Una crítica del derecho de disposición de las partes sobre el material de hecho del proceso), Barcelona, 1943, o que no fundo se trata de desconsiderar o princípio dispositivo; neste livro se pode ler que o princípio dispositivo é "rotina mental" e foram "flexibilizados" com as reformas da Alemanha e Itália dos anos próprios do nazismo e do fascismo (pp. 2 e 3 ).

${ }^{22}$ FURNO, Teoría de la prueba legal, cit., p. 26.
} 


\subsection{A certeza}

Hoje não se pode manter uma noção unilateral da concepção da prova processual determinada de modo absoluto, sem qualquer referência a um determinado direito positivo. É certo que nos últimos anos tem-se tratado de "estabelecer" o critério de que a prova equivale à convicção judicial e, inclusive, ao livre convencimento ${ }^{23}$, mas parece que tal imposição é inadmissível. É o caso, como dissemos, de matizar essa concepção.

Consciente o legislador das dificuldades em obter a verdade metafísíca e a física, bem como de que o processo não pode deixar de estar sujeito a princípios e regras que lhe organizam - alguns dos quais se materializam em garantias processuais essenciais -, ele próprio reconduz a prova à certeza ou se assim se preferir - à existência de elementos suficientes para que se tenham provadas as afirmações fáticas pelas partes, situação em que o próprio legislador assume que essa certeza pode ser atingida de vários modos:

$1^{\circ}$ ) Exclui do objeto da prova as afirmações fáticas feitas pelas partes se sobre elas não haja controvérsia, o que se faz atendendo a natureza dispositiva do direito material que será aplicado. Portanto, os fatos sobre os quais as partes estão de acordo existem para o juiz e ficam excluídos da atividade probatória, e isso vai ao extremo de que, se não existem fatos controvertidos, sequer é o caso de se praticar eventual meio de prova.

$2^{\circ}$ ) Atribui consequências determinantes aos princípios e às regras que organizam o processo, de modo que alguns princípios se apresentam como valores irrenunciáveis, como o da legalidade. Disso importa, sim, o resultado da atividade probatória, mas evidentemente não é menos importante o respeito a esses princípios no desenvolvimento desta mesma atividade.

$3^{\circ}$ ) Algumas vezes estabelece a Lei, e de modo regrado, o valor que o julgador deve conceder a um determinado meio de prova, no sentido de que aí já configura a certeza, independentemente do critério subjetivo do próprio juiz, e isso até o extremo de se referir a uma certeza objetiva. Quando a Lei

\footnotetext{
${ }^{23}$ A situação chegou a tal extremo que CAVALLONE, B., Forme del procedimento e funzione della prova (Ottant'anni dopo Chiovenda), na Rivista di Diritto Processuale, 2006, núm. 2, p. 425, pôde dizer que na atualidade o princípio do livre convencimento do juiz pretende se impor como algo "sagrado" e que pô-lo em discussão em nome da legalidade da prova seria como voltar a cair na "barbárie medieval".
} 
estabelece uma norma de valoração probatória, está dizendo que, por exemplo, a afirmação fática realizada por uma parte, e verificada num documento público, há de ser tida como certa pelo juiz. É dizer, quando isso ocorre deve se ter como provada a afirmação de fato feita por uma parte e isso independe de qualquer referência à convicção psicológica do juiz.

$4^{\circ}$ ) Outras vezes, a Lei dispõe que o juiz deverá atribuir a um certo meio de prova o valor que estime oportuno, sempre de maneira motivada - logo, não de forma discricionária -, com o que a certeza se põe em relação com a convicção psicológica do mesmo juiz, ainda assim se pode concluir que nas atuações existem elementos suficientes para que o respectivo fato possa dar-se como provado. Neste caso caberia falar em certeza subjetiva, não se esquecendo de que não se trata daquilo que o juiz possa decidir conforme a própria “consciência” já que, ainda assim, haverá a necessidade de motivar a sentença de modo a expor de maneira racional como chegou a formar sua convicção, partindo, em todo caso, dos meios de prova contidos no processo.

Dessa maneira não se trata de voltar, por um caminho diferente, à distinção entre verdade material e verdade formal, mas, sim, de que só se pode ter a certeza quando, no procedimento probatório, tenha sido respeitado o princípio da legalidade, de modo que qualquer pessoa possa concluir que estão presentes elementos suficientes para, ao menos, poder dizer que uma afirmação fática pode ser tida como provada. Em sentido contrário, poder-se-á igualmente concluir que uma afirmação fática não deve ser tida como provada independentemente de sua correspondência com a realidade - se do quadro probatório não se permite concluir que estejam presentes elementos que permitam chegar à conclusão de que dada afirmação esteja provada.

\section{Concepções políticas totalitárias e a busca obsessiva da chamada verdade}

\section{objetiva ou material}

Se no tópico anterior expusemos uma breve síntese do que temos chamado de função da prova e seu aspecto jurídico, não podemos esquecer que ao largo do século XX produziu-se uma dogmática do processo civil voltada à persecução daquilo que se chama de verdade objetiva ou material, sendo certo que essa persecução chegou a se converter numa verdadeira obsessão ideológica. Os 
textos legislativos são expressivos nesse sentido, mas o que é mais importante do que isso é a base ideológica que os sustenta.

\subsection{0 processo socialista}

O ponto de partida teórico desta concepção está radicado no final do século XIX em Viena e se personifica em Antón Menger, professor de direito processual civil e fundador do chamado socialismo jurídico. Menger aspirava que transformando os direitos civis privados em direitos administrativos desapareceria a barreira mais importante que separa hoje - dizia ele - os processos civil, penal e administrativo. Tratava-se de que "as três formas de procedimento se fundiriam em uma só, consistente essencialmente em uma instrução de ofício" 24 .

Pouco depois já se estaria diante dessa imposição prática. Quando Lenin dizia que "não reconhecemos nada privado; para nós todo o campo da economia reveste-se de caráter de direito público e não de privado" ${ }^{25}$, estava estabelecendo as bases políticas para a desaparição dos direitos subjetivos privados de todos, mas especialmente os econômicos, e com isso também do próprio processo civil como se o havia compreendido até então. Naturalmente que, por esse caminho, surgiu a consideração fundamental de que o processo civil acabou sendo um "fenômeno social de massas"26. Com isso, fica claro que

\footnotetext{
${ }^{24}$ Sobre Menger pode-se cf. sua biografia em J. L. MONEREO PÉREZ en Juristas universales. 3. Juristas del siglo XIX, Madrid, 2004, pp. 487-494; recordamos que ele foi professor titular de processo civil em Viena quando Klein fazia suas reformas orgânicas e processuais. As citações do texto provêm de MENGER, A., Neue Staatslehre, Jena, 1903, mas citamos a tradução francesa de Milhaud, L'Etat socialista, Paris, 1904, p. 220; existe a tradução espanhola El Estado socialista, Barcelona, 1908. Deve-se cf. ainda PORCAR, V., Il giudice como amministratore: Antón Menger, em "L'Educazione Giuridica. VI-Modelli storici della procedura continentale" (direc. de Giuliani y Picardi), tomo I, Perugia, 1994, pp. 225 e ss.

${ }^{25}$ A citação provém de GURVICH, M., A., Derecho procesal civil soviético, México, 1971 (tradução de Lubán e revisão de H. Cuadra), p. 44.

${ }^{26}$ Por exemplo STALEV, El Procedimiento Civil en los estados socialistas, cit., p. 171. A mesma concepção ideológica se encontra, por raro que possa parecer nos tempos atuais, no juiz federal brasileiro, CABRAL, Antonio do Passo, Il principio del contraddittorio como diritto d'influenza e dovere di dibattito, en Rivista di Diritto Processuale, 2005, 2, p. 453, já citado. Segundo o autor, o direito processual (em geral) tem deixado de lado já há muito tempo as amarras do individualismo, consolidando uma concepção publicista do processo; sendo direito público, deve identificar no exercício da atividade jurisdicional o esforço do Estado para realizar, por meio da jurisdição, alguns fins que são próprios e que precedem aos interesses das partes: objetivos sociais e políticos, entre os quais se deve sublinhar o de assegurar a participação popular no processo; este, o processo, é um meio a serviço de determinados fins estatais e a função jurisdicional é o caminho para alcançar os fins políticos do Estado democrático (se trocamos "democrático" por "soviético", o discurso é exatamente o mesmo). Por isso, não se pode estranhar que o passo seguinte esteja radicado em sustentar que o princípio do contraditório deve ser entendido também como um dever, o que leva a concluir que a participação colaborativa
} 
o mais importante nessa concepção não é a tutela dos direitos da pessoa em si considerada. O mais importante é converter o processo num meio a serviço de determinados fins estatais, fins esses de caráter político a serem cumpridos pela atividade jurisdicional.

$\mathrm{Na}$ intenção de resumir os princípios deste chamado processo socialista, podemos mencioná-los em dois tópicos:

\subsubsection{A verdade objetiva}

A obtenção da verdade objetiva - ou material - foi um princípio essencial do processo socialista, princípio este que correspondia a nada menos que um postulado marxista-leninista ${ }^{27}$, além do que vinha marcado por sua concepção da função do juiz e de sua realização por meio do processo ${ }^{28}$.

O direito socialista, por meio do princípio da verdade objetiva ou material, impunha aos tribunais o dever de adotar todas as medidas necessárias para esclarecer do modo mais completo possível as circunstâncias reais do assunto, as relações jurídicas entre as partes, seus direitos e obrigações. O princípio respondia claramente ao interesse do Estado na realização do direito objetivo e, a partir daí, não atendia à tutela dos direitos subjetivos das pessoas. O importante era fazer efetivo o direito tal como havia sido definido pelo Estado, sendo todo o resto mero acessório ${ }^{29}$.

nas decisões estatais justifica a repressão dos comportamentos de má-fé ou de atos que ofendam a dignidade da justiça; "se está garantida a participação, a conduta deve ser ética, em consonância com os objetivos estatais da jurisdição" (p. 460). Nunca é demais recordar, com MONTELEONE, G., Manuale di Diritto processuale civile, 4. ${ }^{a}$ edição, I, Padova, 2007, p. 21, que instrumentalizar o processo para qualquer fim significa adulterar profundamente a essência de sua função, e isso conduz à supressão do contraditório e à sujeição do juiz, que deixa de ser um sujeito imparcial e independente para assumir o papel de marionete, cujos fios são manejados por outros sujeitos [N.T.: no caso, os donos do poder político].

${ }^{27}$ GURVICH, M. A., Derecho procesal civil soviético, México, 1971 (trad. de Lubán e revisão de H. Cuadra), p. 43, postulado que se denomina de cognoscibilidade, no sentido de que todo homem tem a capacidade de refletir em sua consciência os fenômenos do mundo objetivo; o homem é capaz de conhecer o mundo e a verdade. Mais específicamente, cf. LENIN, Materialismo y empíricocritismo: Notas críticas sobre una filosofia reaccionaria, Barcelona, 1975.

${ }^{28}$ Deve-se ver TROUSSOV, A., Introduction à la théorie de la preuve judiciaire, Moscú, s.d, mas do ano de 1965, traduc. de Piatigorski; GWIAZDOMORSKI y CIESLAK, La preuve judiciaire dans les pays socialistes à l'époque contemporaine, no volume La preuve, Bruxelles, 1963, em «Recueiles de la Société Jean Bodin, XIX», pp. 69 e ss.; CERRONI, U., El pensamiento jurídico soviético, Madrid, 1977, traduc. de Zapatero e De la Rocha, pp. 243 e ss. Também seria útil ver-se VISHINSKI, A., La teoría de la prueba en el derecho soviético, Buenos Aires, 1951, pp. 178 e ss.

${ }^{29}$ Por isso não se pode estranhar que em alguns países socialistas o princípio da verdade objetiva no processo chegou a aparecer na respectiva Constituição, como, por exemplo, na Constituição Checoslovaca de 1960 , 
A partir deste princípio da busca da verdade objetiva ou material é que devem ser compreendidas as faculdades do juiz. Primeiro, a respeito de ele próprio poder realizar atividade voltada a reunir provas no processo. Se o Estado, e no caso o juiz como órgão ou representante do Estado, tinha que conhecer a verdade "verdadeira" existente nas relações jurídicas entre os particulares, as consequências disso tinham que ser: a) para decidir, o tribunal não estava limitado aos fatos alegados pelas partes, de modo que na busca do conhecimento sobre os fatos estavam interessados tanto o tribunal com a procuradoria e várias outras organizações estatais e de representação da sociedade soviética, todos os quais podiam e deviam aportar fatos ao processo; b) o tribunal não devia se conformar com os meios de prova propostos pelas partes, sendo seu dever determinar todas as provas de oficio que entendesse ser oportunas e úteis para se chegar ao conhecimento da chamada verdade objetiva. ${ }^{30}$

O princípio da verdade objetiva gerava a consequência de que o juiz podia, ou melhor, devia, adotar todas as medidas tendentes ao esclarecimento total das circunstâncias do assunto, incluindo, obviamente, o poder de determinar a produção de meios de prova de ofício. Não se tratava de uma faculdade do juiz, mas de um dever, e a finalidade não era propriamente a tutela dos direitos dos particulares (os quais, para esta concepção, tinham importância secundária, se é que se pode dizer que tinham real importância), mas sim a defesa do Direito objetivo, o qual devia ser aplicado sempre que se estivesse diante de um suposto fático daqueles previstos, abstratamente, na norma. ${ }^{31}$

onde se dizia no artigo 107: "Os tribunais realizarão um processo de tal modo que se conheça o estado real das coisas sobre as quais deliberam".

${ }^{30}$ KELLNER, H., Introduzione a la Ordinanza della procedura civile della Repubblica Democratica Tedesca, 1975, Milano, 2004, no volume X de "Testi e documenti per la Storia del Processo", dirigidos por Picardi e Giuliani (o trabalho de Kellner foi escrito nos anos oitenta do século XX). Também pode ter interesse CAPPELlETTI, M., El proceso civil en el derecho comparado, Buenos Aires, 1973 (tradução de Sentís Melendo).

${ }^{31}$ Neste sentido, por exemplo, pode-se cf. Principios (o Bases) fundamentales del procedimiento civil de la URSS y de las Repúblicas Federadas, de 1961:

1) Princípio $16^{\circ}$ : Declaração dos fatos da causa, dos direitos e das obrigações das partes: o juiz, sem limitação alguma e independente de material levado ao processo e das declarações prestadas pelas partes, adota todas as medidas previstas pela lei a fim de alcançar um completo, minucioso e objetivo conhecimento dos fatos da causa, além dos direitos e obrigações das partes. O juiz deve orientar as pessoas que intervêm no processo sobre seus direitos e obrigações.

2) Princípio 18. : Ônus da prova e obrigação de praticar os meios de prova: depois de decidir que os meios de prova devem ser propostos pelas partes "e pelas demais pessoas que intervêm no processo", acrescenta: "Se as provas propostas resultarem insuficientes, o juiz ordena às partes e a outras pessoas intervenientes no processo que proporcionem outros meio de prova, ou os determinara de ofício". 
Naturalmente que neste contexto o juiz não é um terceiro entre as partes e tampouco se pode considerar imparcial, já que - afinal - não exerce propriamente jurisdição, ao menos tal como a entendemos no mundo ocidental. O juiz é um "funcionário" do Estado a quem se confia uma espécie de atos de jurisdição voluntária, atos por meio dos quais se aplica o Direito objetivo sem importar com o que as partes alegam e tampouco com os interesses que querem defender.

\subsubsection{A colaboração do juiz e das partes}

Uma das diretrizes constantes na doutrina comunista sobre o processo civil é a ideia relativa a que o respectivo processo não se apresenta como uma sorte de contenda entre partes, não é uma "luta" entre elas, de modo que a busca da verdade material se resolve em um princípio que se pode denominar de colaboração entre todos os que intervêm no processo, e assim se fala de uma "colaboração de confiança entre o juiz e as partes" 32 . Deste modo se destacam:

i) O dever do juiz de assessorar as partes sobre os direitos e obrigações que lhes correspondem, o que supõe também a necessidade de estimular a atividade processual das partes e, a rigor, de todos os demais sujeitos que intervêm no processo, chegando-se a falar de uma sorte de funções assistenciais encomendadas ao juiz para que possa operar mesmo quando as partes comparecem assistidas por seus advogados. ${ }^{33}$

ii) Correlativamente o dever das partes não é aportar os fatos ao processo informando-os ao juiz, mas sim fazê-lo de modo a não esconder fato algum, fazendo-o sempre de maneira veraz, de modo que há de chegar ao processo tudo

\footnotetext{
Posteriormente o Código de procedimiento civil de República Socialista Federal Soviética de Rusia, de 1964, previu que os princípios anteriores se aplicavam literalmente. Estes dispositivos legais podem ser consultados em Codice di procedura civile della Repubblica Socialista Federativa Sovietica di Russia, Milano, 2004, no volume IX de "Testi e documenti per la Storia del Processo", dirigidos por Picardi e Giuliani, aqui já citado.

${ }^{32}$ Por exemplo KELLNER, Introduzione, cit., p. XLIX.

${ }^{33} \mathrm{Cf}$, por exemplo, em STALEV, El proceso civil en los Estados socialistas, cit., p. 195. Segundo o artigo 2 (2) do que se chamava Código de Procedimiento Civil de la República Democrática Alemana, de 1975: "Os tribunais têm o dever de esclarecer e declarar, de forma verdadeira, e decidir segundo as normas de direito, em um proceso concentrado e rápido, os fatos relevantes para o juízo". E seu artigo 2 (3): "Os tribunais devem indicar aos que participam do proceso seus respectivos direitos e obrigações para que os mesmos se façam efetivos". Este dispositivo legal pode ser cf. em Ordinanza della procedura civile della Repubblica Democratica Tedesca, 1975, Milano, 2004, no volume X de "Testi e documenti per la Storia del Processo", dirigidos por Picardi e Giuliani, já citado.
} 
aquilo sobre o que as partes têm conhecimento. Trata-se de um dever de veracidade e integridade, de muito maior alcance que o dever de lealdade e probidade. ${ }^{34}$

Taruffo tem sustentado que esta concepção deve se referir a um contexto ideológico e filosófico absolutamente peculiar, já que determinou a ortodoxia da cultura processualista dos países socialistas e hoje não merece nada mais do que ser mencionada por razões apenas de exigências historiográficas ${ }^{35}$. Contudo, não deveria se esquecer de que alguns de seus mais relevantes aspectos (por exemplo, a prova de ofício, ou os deveres de boa-fé e veracidade) continuam dando suporte à construções teóricas que pedem suas inclusões em diplomas legais concretos, sem que tais construções esclareçam quais são as bases ideológicas de umas (=teorias) e de outros (=diplomas legais concretos).

Parece-nos muito razoável exigir, ao menos, que se ponham às claras quais são as bases dogmáticas ideológicas daqueles que sustentam aquelas construções e daqueles que insistem em que se lhas incluam nos códigos, de lege lata ou de lege ferenda. Não é legítimo, portanto, seguir sustentando que tudo isso não passa de meras questões técnicas.

\subsection{0 processo fascista}

Também em Viena e também ao final do século XIX encontramos Franz Klein, que em 1891 fora nomeado chefe de seção do Ministério da Justiça e que põe em marcha as "leis da justiça" 36. Entre as várias leis que impulsionou, e depois já como Ministro, a que aqui nos importa é Ordenanza Processual Civil, que foi aprovada em $1895^{37}$ e entrou em vigor em $1^{\circ}$ de janeiro de $1898^{38}$. No

\footnotetext{
${ }^{34}$ Segundo o artigo 3 ("Direitos e obrigações das partes") (1) do Código de Procedimiento Civil de la República Democrática Alemana, de 1975: “... As partes têm o direito e o dever de participar do processo e, especialmente, de colaborar para a declaração da situação de fato. Suas respectivas declarações e depoimentos devem ser completos e verdadeiros".

${ }^{35}$ TARUFFO, La prueba de los hechos, cit., pp. 58-59.

${ }^{36}$ Sobre Klein, pode-se ver sua biografia de W. BRAUNEDER em Juristas universales. 3. Juristas del siglo XIX, Madrid, 2004, pp. 647-650.

${ }^{37}$ Nesse período Antón Menger era professor de processo civil em Viena e exatamente no ano de 1895 foi guindado ao mais elevado posto acadêmico, de professor titular; cf. MONEREO PÉREZ, José Luis, Antón Menger, cit., pp. 488, sem esquecer que, apesar do que afirma seu biógrafo, a posição de Menger não era nem liberal nem democrática.

${ }^{38}$ Cf. Ordinanza della procedura civile di Francesco Giuseppe. 1895, que é o núm. VIII da coleção Testi e documenti per la storia del processo, dirigida por Picardi e Giuliani, Milano, 2004, com a introdução de W. H.
} 
final do século XIX governava o império austro-húngaro Francisco José I de Hadsburgo, como Imperador da Áustria e Rei da Hungria. Não há correspondência nenhuma entre esse sistema político e a democracia liberal.

Curiosamente, também para Klein o processo se convertia num fenômeno social de massas ou em uma das instituições sociais do Estado ${ }^{39}$. O processo é um mal social e, portanto, o interesse do Estado é concluí-lo o quanto antes e sob o menor custo possível ${ }^{40}$. Estas são as bases ideológicas de Klein e o processo devia ser entendido como uma espécie de procedimento administrativo no qual se tutelam desde logo os interesses individuais, mas também, e especialmente, os interesses sociais ${ }^{41}$. Neste contexto, um dos elementos definidores desse processo é o reforço dos poderes do juiz, o qual não pode seguir sendo um mero contemplador da contenda, posto que deve proteger não só o indivíduo, mas também o Ordenamento Jurídico a serviço da comunidade ${ }^{42}$, o que inclui o poder de determinar a chamada prova de ofício. ${ }^{43}$

O juiz não se limita a julgar, é o gestor (administrador) do processo, dotado de grandes poderes discricionários que devem estar a serviço de garantir

Rechberger e G. E. Kodek (pp. IX-XXXV) e a de C. Consolo, esta intitulada Il duplice volto della "buona" giustizia civile tardo-asburgica e del suo rigeneratore ( $\mathrm{pp}$. XXXVII-LXV).

39 A obra de referência desta concepção é a de KLEIN, F., Materialen zu den neuen österreichischen Civilprozessgesetzan, Viena, 1897. Sobre ela pode-se cf. FAIRÉN, V., El proyecto de Ordenanza Procesal Civil austriaca visto por Franz Klein, em "Estudios de Derecho Procesal”, Madrid, 1955, págs. 301 e ss. Klein chegava a falar de processo civil como uma "instituição de beneficência" ou de um instituto dirigido a provomer o bem-estar coletivo e, a partir daí, com a consequente função social do juiz. É evidente aqui a influência de Menger; este considerava que o juiz não devia ser um terceiro imparcial, pois devia assegurar a assistência e a instrução da parte mais fraca, e na mesma linha Klein fala do processo como meio para educação e bem-estar social (cf. PORCAR, Il giudice como amministratore: Antón Menger, em "L'Educazione Giuridica. VI", tomo I, cit., p. 231).

40 Neste sentido SPRUNG, R., Le basi del diritto processuale civile austriaco, em Rivista di Diritto Processuale, 1979, p. 38. Também CIPRIANI, F., Nel centenario del Regolamento di Klein (Il processo civile tra libertà e autorità), em Rivista di Diritto Processuale, 1995, depois publicado em Idelogie e modelli del processo civile. Saggi, Napoli, 1997 e, por fim, em Batallas por la justicia civil, Lima, 2003 (tradução de Ariano); cito desde esta última publicação, e na p. 65. Também se pode ver PARRA QUIJANO, J., Racionalidad e ideología en las pruebas de oficio, Bogotá, 2004, pp. 39 e ss.

${ }^{41}$ Outra vez SPRUNG, Le basi del diritto, cit., p. 36.

42 Neste sentido FASCHING, em palestra austríaca citada por FAIRÉN, Los procesos europeos desde Finlandia hasta Grecia (1990-1975), em "LXXI años de evolución jurídica en el mundo", México, 1978, p. 28. Depois na Introdução de W. H. RECHBERGER e G. E. KODEK (p. XXVII) à Ordinanza della procedura civile di Francesco Giuseppe. 1895, antes citada, pode-se ler que a Ordenanza está sujeita a um "princípio inquisitivo atenuado" e que o processo civil austríaco se caracteriza "principalmente pela chamada iniciativa do juiz".

${ }^{43}$ Para GOLDSCHMIDT, J., Derecho procesal civil, Barcelona, 1936 (trad. de Prieto Castro e notas de AlcaláZamora), p. 40, na ZPO austríaca "a reunião dos elementos do processo se obtém pela colaboração do juiz com as partes, graças a uma feliz fusão do princípio dispositivo e o oficial, ou inquisitivo", além de viabilizar a possibilidade de determinar provas de ofício e da imposição de deveres ou obrigações às partes. 
não só os direitos das partes, mas principalmente os valores e interesses da sociedade. ${ }^{44}$

\subsubsection{Alemanha e o nazismo}

A Ordenanza Processual Civil de 1877 pode-se considerar liberal ${ }^{45}$ e, chegada a época do nazismo, ainda que não se tenha positivado outra Ordenanza, defendia-se ${ }^{46}$ que o denominador comum das elaborações do regime político foi a tirânica acentuação do critério coletivista da "comunidade do povo" ${ }^{47}$, no qual se pautava, dentre outras coisas, a exaltação da figura do juiz que, por outro lado, converteu-se em dependente do poder nazista. Como dizia o Ministro da Justiça Hans Frank, o juiz deve ser sempre consciente de que "em razão de sua posição predominando na aplicação do direito, não pode jamais ir contra os princípios do programa político nacional-socialista e de sua ideologia". ${ }^{48}$ A concepção de processo civil, não a extrema, em que se quis convertê-1o em mera jurisdição voluntária ${ }^{49}$, mas a menos radical de Hans Otto

\footnotetext{
${ }^{44}$ FAIRÉN, El proyecto de Ordenanza Procesal Civil..., cit., pp. 315-6: "É lamentável, dizia Klein, que em determinada porcentagem as sentenças, quando confrontadas com a realidade dos fatos, venham a resultar injustas ou defeituosas"; isso ocorre em muitos casos por falta de diligência; em outros, por ver-se o juiz diligente obrigado a julgar sobre uma base de fatos injustos, incertos e duvidosos. Por isso Klein aumenta os poderes do juiz, o qual pode completar o processo naquilo que lhe falte, é dizer, pode determinar quantos meios de prova estime oportunos.

${ }^{45}$ Para LEIBLE, S., Proceso civil alemán, Medellín, 1999, pp. 64-65, a ZPO de 1877, influenciada pela codificação napoleônica, estava "assentada totalmente numa concepção liberal de Estado", de modo que a lei era o regramento da luta entre as partes, na qual estas assumiam sua responsabilidade, sendo o juiz um terceiro neutral. Já GOLDSCHMIDT, James, Derecho procesal civil, Barcelona, 1936 (trad. de Prieto-Castro e notas de Alcalá-Zamora), p. X, havia dito que o processo alemão era um "vestido liberal do século XIX ao qual se tinha costurado muitos remendos surgidos dos tempos passados".

${ }^{46}$ BÖHM, P., Processo civile e ideologia nello stato nazionalsocialista, em Rivista Trimestrale di Diritto e Procedura Civile, 2004, núm. 2, pp. 623 e ss. (o trabalho é de 1990, e apareceu publicado no volume coletivo Nationalsozialismus und Recht, Viena, 1990).

${ }^{47}$ Em matéria penal essa "comunidade do povo" deu lugar à legislação sobre os "estranhos à comunidade", e um exemplo disso pode se ver em MUÑOZ CONDE, F., Edmund Mezger y el Derecho Penal de su tiempo.

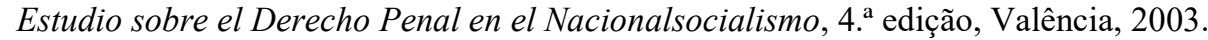

${ }^{48}$ Citado por BÖHM, Processo civile e ideologia nello stato nazionalsocialista, cit., pp. 629-630.

${ }^{49}$ BAUMBACH, A., Zivilprozess und freiwillige Gerichtsbarkeit (Proceso civil y jurisdicción voluntaria), em Zeitschrift der Akademie für deutsches Recht, 1938, pp. 583 e ss; depois, em 1941, pp. 31-49, e em 1942, p. 49. Para sua exposição crítica na Itália CALAMANDREI, P., Abolizione del processo civile?, em Rivista di Diritto Processuale Civile, 1938, I, pp. 336-340, e depois em Opere giuridiche, I, Napoli, pp. 387-390; e na Espanha PRIETO CASTRO, L., Revisión de los conceptos básicos de derecho procesal, em Estudios y comentarios para la teoría y la práctica procesal civil, II, Madrid, 1950, pp. 665-669. Ultimamente foi recordado por CAPONI, R., I poteri probatorie delle parti e del giudice nel processo civile tedesco dopo la riforma del 2001, em "Prove nel processo civile", Atti del XXV Convegno Nazionale, nos Quaderni dell'Associazione fra gli Studiosi del Processo Civile (Cagliari, 7-8 ottobre-2005), Milano, 2007.
} 
de Boor ${ }^{50}$, sustentava: "Que para nós, no Terceiro Reich, não nos serve para nada um processo de inspiração e características liberais, é coisa totalmente evidente, sobre a qual não se deve dar nem sequer uma explicação". Negavase, pois, a concepção do juiz como sujeito neutral que assiste a luta entre duas pessoas; era necessário um juiz que "tutele os interesses da comunidade do povo de modo extremadamente ativo". Esse juiz tampouco tutelava os direitos subjetivos dos cidadãos, já que sua função consistia em levar a termo, na prática, o Direito objetivo, o qual era expressão da ideologia nazista.

$\mathrm{Na}$ Exposição de Motivos da Lei de 1933, que modifica o procedimento civil na Alemanha, dizia-se: “As partes e seus representantes devem ser conhecedores de que a jurisdição não serve só a elas, senão que serve antes e principalmente à atuação da paz de toda a comunidade". Mas ainda assim se tratava, como disse Böhm, de que as disposições programáticas da Lei de 1933 impunham ao juiz uma "rigorosa direção do processo", o "efetivo descobrimento da verdade", e uma disciplina de procedimento "dinâmica", "compreensivel" e "autenticamente popular". 51

Maior incidência teve, ainda, a Lei de 15 de julho de 1941, sobre a participação do Ministério Público nas controvérsias civis. Com ela, o Promotor de Justiça [=Fiscal] assumia em todos os processos civis, mais ou menos como o Promotor soviético, a posição de pretensa parte imparcial, com poder para alegar fatos e para propor a produção de provas. Desta maneira o princípio da aportação vinha completamente alterado, sendo um primeiro passo no caminho da imposição do princípio inquisitivo no processo civil. Tratava-se de sacrificar a estrutura bilateral do processo e por isso a Lei foi qualificada de "giro crucial" na evolução do direito.

\subsubsection{Itália e o fascismo}

A concepção do processo civil do fascismo italiano é revelada na Relazione (Exposição de Motivos) do Código processual civil de 1940, redigida por

\footnotetext{
${ }^{50}$ A síntese de DE BOOR pode ser vista em BÖHM, Processo civile e ideologia nello stato nazionalsocialista, cit., pp. 631-633; trata-se do artigo publicado também na Zeitschrift der Akademie für deutsches Recht, 1938, pp. 834 e ss. e intitulado Die Funktion des Zivilprozesses (A função do processo civil).

${ }^{51}$ BÖHM, Processo civile e ideologia nello stato nazionalsocialista, cit., p. 639.
} 
Calamandrei apesar de assinada por Dino Grandi, então Ministro da Justiça ${ }^{52}$. Sem maiores dificuldades nessa Relazione se encontra:

i) O novo Código se baseia num condicionamento político; se o Código anterior, o de 1865, era expressão dos interesses individuais que estavam à base do Estado Liberal, o Código de 1940 queria ser a expressão do Estado Fascista. Para este, o processo civil não é apenas a luta entre interesses privados; é também instrumento para assegurar que as normas ditadas por esse Estado sejam cumpridas (cf. na Relazione, "2.- Os fatores históricos da reforma”).

ii) Um dos pontos fundamentais do Código de 1940 foi o aumento dos poderes do juiz (cf. na Relazione, "8.- O juiz e a lei"), que foi qualificado como "diretriz fundamental da Reforma", mas isso é de ser entendido dentro do "renovado conceito da dignidade e da autoridade do Estado fascista e de seus órgãos" 53 (cf. Relazione, "12.- Reforço dos poderes do juiz para a direção do processo"). ${ }^{54}$

\footnotetext{
${ }^{52}$ Estamos fazendo referência à Relazione ou Exposição de Motivos que precede o Código, que foi escrita por Calamandrei e assinada pelo Ministro Dino Grandi. A Relazione al Re havia sido esquecida depois de não ter sido publicada desde 1943, cf. CIPRIANI, D'ELIA e IMPAGNATIELLO, Codice di procedura civile con la Relazione al Re, cit., mas é evidente que expressa politicamente o que o Código desenvolve em seus artigos. Ultimamente, parte da doutrina está chegando ao extremo de imputar a quem cita a Relazione [=Exposição de Motivos] uma espécie de má-fé argumentativa quando se faz referência à ideologia do Codice, de modo que parece que se quer negar sua existência (p. ex., CHIARLONI, S., Le recenti riforme del processo civile, Bologna, 2007, p. 154). A situação chega a certo ponto que é possível, neste momento, começar a se acreditar em milagres; ou, pelo menos, passar a acreditar que a Itália fascista de 1940 tenha produzido um Codice que, apesar de tudo, é liberal e democrático. Ou seja: milagre! Resta saber a quem devemos atribuí-lo para dar início ao seu processo de beatificação...

${ }^{53}$ Deveria ser desnecessário ter que recordar que o próprio CALAMANDREI, na Avvertenza à primeira edição das Istituzioni di diritto processuale civile secondo il nuevo codice, Parte prima, Padova, 1941, p. X, disse: "Uma das maiores virtudes do novo Código, quiçá sua mais apreciável novidade, é sua adequação histórica: a consciência que teve o legislador em relação à posição que a justiça ocupa no Estado e da necessidade de considerar também as instituições judiciais como expressão de um certo clima histório, não alheias à realidade social, senão também tendo suas raízes bem fincadas no terreno político de seu própio tempo" (na segunda edição de 1943, ainda que sua Avvertenza seja datada em dezembro de 1942, reiterada na p. XI). Desta maneira, resulta algo aparentemente estranho mas que, sem bem pensadas as coisas, não o é; alguns primeiro negam, sem mais, que o Código seja fascita para poder, na sequência, defender o que está sustentado no Código e, ao final, há os que, como nós, vemos que o "Rei segue nu" [=el Rey va desnudo] (JUAN MANUEL, Conde Lucanor, 1335, Conto XXII, "Lo que sucedió a un rey con los burladores que hicieron el paño"), ou seja, que o Código só pode mesmo ser fascita, muito embora com isso podemos acabar sendo acusados de "revisionistas".

${ }^{54}$ Este conjunto de caracteres que determinam o que é um Código fascista têm uma explicação doutrinária de relevo no Capítulo Terceiro das Istituzioni de CALAMANDREI, P., Istituzioni di diritto processuale civile secondo il nuovo codice, Parte prima, Padova, 1941, pp. 233 e ss. Nesse Capítulo é necessário ler os parágrafos 57, sobre o princípio da autoridade no processo, o 59, sobre o princípio dispositivo, mas especificamente na parte atinente à iniciativa probatória do juiz, e o 61, sobre a intensificação do dever cívico de colaboração com a justiça. As diferenças são muitos apreciáveis se comparadas com a obra de CARNELUTTI, F., Instituciones del Nuevo proceso civil italiano, Barcelona, 1942 (tradução de Guasp).
} 
A partir dessas considerações o Código dedicou um Título (o V do Livro I) denominado "Dos poderes do juiz", e principalmente em matéria de prova aos juízes foram atribuídos poderes de ofício para: a) determinar a qualquer momento do processo o interrogatório das partes (art. 117), b) determinar o reconhecimento de pessoas (partes ou terceiros) e de coisas (art.118), c) deferir o juramento supletório (arts. 240 e 241 do CPC, e art. 2.736 do CC), d) formular à testemunha qualquer pergunta que entenda útil para esclarecer os fatos (art. 353), e) decretar acareações (art. 254), f) determinar o comparecimento de testemunhas referidas (art. 257) etc. E não se esqueça que no processo do trabalho o art. 421 permite ao juiz determinar qualquer prova e a qualquer momento, independentemente de pedido da parte interessada. ${ }^{55}$

\subsubsection{Espanha e os fatos no processo de Guasp}

Neste momento poderíamos fazer menção também a Portugal e a seu Código de Processo Civil de 1939 junto com a obra de José Alberto dos Reis ${ }^{56}$, mas não é o caso de, agora, seguir-se examinando os códigos de outros países originados mais ou menos na mesma época, isto é, antes da II Guerra Mundial. ${ }^{57}$

Algum dia se haverá de comparar a ideologia processual franquista (se é que existiu) com a nazista, a fascista e o salazarismo português, para análise de similitudes e diferenças entre elas, mas no momento basta informar que na Espanha franquista não houve alterações de transcendência no processo civil.

\footnotetext{
${ }^{55}$ Uma síntese pode ser vista hoje, por exeplo, em CONTE, M., Le prove nel processo civile, Milano, 2002, pp. 31-32.

${ }^{56}$ MENDONÇA, L. C. de, Direito processual civil. As origens em José Alberto dos Reis, Lisboa, 2002, e 80 anos de autoritarismo: uma leitura politica do processo civil português, no volume "Proceso civil e ideología" (coord. Montero), Valencia, 2006, pp. 381 e ss, O pensamento de Franco Cipriani sobre a justiça civil, em Revista do Centro de Estudos Judiciários, 2005, núm. 2, pp. 65-125.

${ }^{57}$ Não é fácil resistir a indicar o disposto no artigo 481 do Código português de 1939, no qual se assume a reforma introduzida pelo Decreto Lee de 22 de setembro de 1926: O juiz deve indeferir a petição inicial [=rechazar la demanda]: “d) Quando a injustiça da pretensão do autor seja tão evidente que resulte inútil qualquer instrução da causa". Esta inovação foi qualificada de "autêntica revolução" por seu ideólogo, J. A. DOS REIS, O novo Código de Processo Civil Portugués, no Boletim da Faculdade de Direito da Universidade de Coimbra, suplemento VI, 1945, p. 343, citado por MENDONÇA, Direito processual civil, cit., p. 156; mas também se deve ver DOS REIS, La riforma del processo civile portoguese, na Rivista di Diritto Processuale, 1930, I. Por certo que esta "revolução" salazarista foi assumida no artigo 427 do Código Processual Civil do Peru de 1993 e é necessário ver a defesa de MONROY GÁLVEZ, J., Introducción al proceso civil, tomo I, Bogotá, 1996; a citação feita aqui é a de ARIANO DEHO, E., ¿Diez años de eugenesia procesal? Los artículos 426 y 427 del Código Procesal Civil, em "Derecho Procesal Civil. Congreso Internacional”, Lima, Universidad de Lima, 2003, pp. 119-135.
} 
Apesar disso, não posso deixar de recordar o pensamento de Jaime Guasp $^{58}$ expressado em seu livro Juez y hechos en el proceso civil, de 1943, pensamento que deve ser entendido como imerso na concepção fascista do processo $^{59}$. Não se trata agora de pretender resenhar todo esse pensamento, mas simplesmente recordar que para Guasp a tendência em aumentar os poderes do juiz, tal e como estava sendo feito na Alemanha e na Itália - que Guasp qualificava de "correntes modernas" -, fazia parte da reforma radical que precisava ser feita na justiça civil, reforma do princípio dispositivo ao que se opunha à "rotina mental", chegando mesmo a sustentar que o aforismo secundum allegata et probata partium, judex judicare debet, que na Espanha havia sido convertido num dogma jurídico, explicava-se pelo entroncamento do nosso sistema com as práticas medievais ${ }^{60}$. Obviamente que o passo seguinte é a pretensão de que um futuro código teria que superar essa velha concepção.

Em síntese, parece evidente que as concepções fascistas partem ideologicamente de algum matiz distinto da concepção socialista, mas nos dois casos se trata da busca da verdade chamada material ou objetiva, não para a tutela dos direitos do cidadão, é dizer, do interesse individual, mas sim para levar a efeito o que o Estado decidiu que é o interesse geral ao plasmá-1o no Direito objetivo; este deve se impor sempre, e por isso nos dois casos o juiz não é nem terceiro nem imparcial entre as partes.

\section{A tomada de uma outra concepção}

$\mathrm{Na}$ segunda metade do século XX produziram-se dois fenômenos concorrentes. De um lado vimos a relativização da verdade na hora de fixar a

\footnotetext{
${ }^{58}$ Cf. M. FENECH no seu La posición del Juez en el Nuevo Estado, Madrid, 1941, ainda que o prólogo deste livro seja de Guasp.

${ }^{59}$ GUASP, J., Juez y hechos en el proceso civil (Una crítica del derecho de disposición de las partes sobre el material de hecho del proceso), Barcelona, 1943, publicado agora também em Estudios jurídicos, cit., pp. 279390.

${ }^{60} \mathrm{O}$ que para o livro Juez y hechos en el proceso civil eram "práticas medievais", posteriormente no manual Derecho procesal civil, 3. a edición, 2. a reimpresión, Madrid, 1977, pp. 316-317, eram "ordenamentos primitivos da instituição processual"; é dizer, para Guasp, não apenas na obra de 1940, senão até o final de sua vida, "a exclusividade da atividade de alegação a cargo das partes, segundo o qual, a teor do velho aforisma iudex iudicare debet secundum allegata et probata partium, não é senão uma arcaica reminiscência de ordenamentos primitivos da instituição processual. A finalidade característica do processo não ficaria desnaturalizada ainda que fosse atribuída ao juiz a possibilidade de aportar dados ao processo, sempre que se mantivesse em vigor, e radicalmente separada, a distinção entre pretensão processual e as meras alegações, de modo a se garantir a exatidão lógica do julgado".
} 
função do processo civil, mas por outro lado a verdade objetiva se converteu politicamente no fim do processo civil e, ao menos, na função essencial da prova. Trata-se obviamente de algo que pode parecer contraditório, mas não é, se bem que isso nos leva a questionar o que está por trás de códigos aparentemente pouco politizados. ${ }^{61}$

Por exemplo, no Código de Processo Civil Modelo para a Iberoamérica está disposto que dentre as faculdades do tribunal está a de "ordenar as diligências necessárias para esclarecer a verdade dos fatos controvertidos, respeitando o direito defesa das partes" (art. 33, $4^{\circ}$ ) e, na sequência, entre seus deveres refere-se a "empregar as faculdades e poderes que the concede o Código para a direção do processo e a averiguação da verdade dos fatos alegados pelas partes" (art. 34.2), devendo ser entendido que o não cumprimento destes deveres acarretará na responsabilização funcional da autoridade judicante.

A persecução da pretendida verdade é muito mais grave do que pode parecer. Uma coisa é partir do pressuposto de que - ainda que com as limitações antes apontadas - o normal é que no processo civil se chegue à verdade de como ocorreram os fatos, posto que as limitações operam de um modo não geral, mas em situações de processos concretos, e outra, muito diferente, em que se entende que a "justiça" do caso concreto apenas é atingida quando se alcança a verdade objetiva, pois então a tentação leva a ignorar princípios essenciais do processo civil, como os princípios dispositivo e do contraditório.

Hoje é difícil alguém sustentar de modo aberto o princípio da verdade objetiva, ao menos na sua derivação decorrente da doutrina marxista-leninista de que o homem é capaz de conhecer o mundo e a verdade, pelo que não se pode

\footnotetext{
${ }^{61}$ Dizia DENTI, V., La evolución del derecho de las pruebas en los procesos civiles contemporáneos, em Estudios de derecho probatorio (tradução de Sentís e Banzhaf), Buenos Aires, 1974, p. 152, que a concepção do processo como adversary system respondia a uma concepção liberal e democrática (no sentido ocidental) da sociedade civil, mas que a queda destes valores, seja quanto aos fins em si mesmos (caso dos regimes ditatoriais fascistas), seja em relação ao valor justiça (caso dos regimes ditatoriais socialistas), inevitavelmente leva à atenuação da iniciativa das partes e à afirmação dos poderes do juiz.

Se deixarmos de lado as expressões claramente sectárias de Denti (tal como dizer que a derrocada da liberdade e da democracia nos países socialistas responde a uma ideia superior de justiça), é evidente que para o antigo professor de Pavía a atenuação da iniciativa das partes e o aumento dos poderes do juiz responde a bases sem dúvida alguma políticas, e precisamente de conteúdo muito bem determinado. Por isso, causa estranheza que o seu sucessor de cátedra chegue a negar a conexão entre o aumento dos poderes probatórios do juiz e os regimes políticos autoritários e antidemocráticos (assim o faz TARUFFO, Poteri probatori delle parti e del giudice in Europa, cit., pp. 468 e ss).
} 
pôr barreiras ao conhecimento, nem é imaginável que se siga sustentando que a verdade supõe coordenação entre as declarações e a realidade objetiva, aqui entendido que essa verdade não se identifica com a verdade absoluta. Tampouco ninguém se atreveria a sustentar que se chegar a essa verdade objetiva é algo que passa ao largo dos princípios dispositivo (manifestação dos inexistentes direitos privados de natureza econômica) e do contraditório (qualificado como expressão hipócrita do interesse da classe dominante). Da mesma maneira que não é fácil encontrar alguém que defenda que a verdade material, com o aumento dos poderes que implica, justifica-se com referência ao "renovado conceito da dignidade e da autoridade do Estado fascista e de seus órgãos".

Hoje, ninguém se soma a essas bases ideológicas de modo claro, mas o certo é que seguem sendo registradas manifestações doutrinárias e práticas onde se defende que a prova deve perseguir a verdade material ou objetiva, e com esse fim o juiz deve poder determinar provas de ofício; nessas situações, seria conveniente que fossem explicadas publicamente quais são as bases ideológicas das quais partiram. ${ }^{62}$

Espero por isso já há algum tempo. Mais de uma década. Porém em vão.

\footnotetext{
${ }^{62}$ Não se colocam de manifesto as bases ideológicas, ao contrário, são escondidas quando (assim o faz TARUFFO, Poteri probatori delle parti e del giudice in Europa, cit., pp. 476-477), partindo do princípio de que se opta por um sistema onde importa a qualidade da decisão que resolve o processo, a qual deve estar baseada numa declaração verdadeira dos fatos da causa - algo que qualquer pessoa está disposta a afirmar como algo evidente, ainda que se esqueça dos limites constitucionais à busca incessante dos fatos -, passa-se a sustentar que, para se atingir essa finalidade, necessita-se de um juiz que "possa integrar as iniciativas probatórias das partes quando estas pareçam insuficientes ou inadequadas para que se prolate uma sentença que declare a verdade dos fatos". As bases ideológicas são reveladas, ainda que veladamente, quando é sustentado seguidamente por Taruffo que: 1) Em todos os processos há sempre uma parte que não tem interesse em que se descubra a verdade, e 2) Em todos os processos os Advogados não perseguem a busca imparcial e desinteressada da verdade, mas, sim, têm interesse em ressaltar a versão dos fatos que seja mais conveniente à parte que defendem. Aqui já se mostra que se está partindo de uma maneira evidentemente ideológica de negar dois elementos essenciais que estão na base na civilização ocidental, pois o que se está dizendo é que: 1) Os cidadãos não podem ter, em todas as situações, o direito de defender em juízo o direito que estimam ter, e 2) Os advogados, que se consideram elementos perturbadores da "justiça", não deveriam atuar como defensores desses direitos. Quem sustenta suas considerações fundadas nesses pressupostos nada mais precisa dizer para confirmar quais são suas bases ideológicas.
} 